\title{
EXTRAÇÃO E DETERMINAÇÃO, POR CLAE, DE BIXINA E NORBIXINA EM COLORÍFICOS ${ }^{1}$
}

\author{
Luciane TOCCHINI ${ }^{2}$, Adriana Zerlotti MERCADANTE ${ }^{3, *}$
}

\begin{abstract}
RESUMO
Um dos atributos mais importantes na comercialização de alimentos é o impacto visual causado pela cor. Entre os corantes naturais, o urucum é o mais usado pela indústria brasileira. Do total de sementes de urucum industrializada no Brasil, $25 \%$ são utilizados na preparação dos extratos e o restante é empregado na fabricação do colorífico, consumido no mercado interno para o preparo doméstico de alimentos. A proposta deste trabalho foi determinar o teor de bixina e norbixina nos coloríficos de urucum existentes no mercado, utilizando cromatografia líquida de alta eficiência. Empregaram-se, para tanto, coluna $\mathrm{C}_{18}$ (Spherisorb ODS-2, $150 \times 4,6 \mathrm{~mm}, 3 \mu \mathrm{m})$ e acetonitrila:ácido acético $2 \%$ (65:35) como fase móvel com fluxo de $1 \mathrm{~mL} / \mathrm{min}$. Os carotenóides foram identificados através do comportamento cromatográfico e espectros no UV-visível fornecidos pelo detector de arranjos de diodos; e quantificados por padronização externa. Foram analisadas sete marcas diferentes de colorífico (de dois a cinco lotes de cada marca), totalizando vinte e cinco amostras. A bixina foi o carotenóide majoritário encontrado nas diferentes marcas de colorífico, em teores que variaram de 154 a $354 \mathrm{mg} / 100 \mathrm{~g}$, enquanto a norbixina esteve presente em traços ( 2 a $9 \mathrm{mg} / 100 \mathrm{~g}$ ). A variação dos teores de carotenóides foi pequena entre lotes da mesma marca, enquanto foi observada uma grande diferença em relação às diferentes marcas analisadas.
\end{abstract}

Palavras-chave: carotenóides; urucum; colorífico; bixina; norbixina.

\section{SUMMARY}

EXTRACTION AND DETERMINATION OF BIXIN AND NORBIXIN IN ANNATTO SPICE ("COLORÍFICO"). One of the most important factors for food commercialization is the visual impact due to color. Among the natural colors, annatto preparations are the most consumed colorant by Brazilian industries. From the total amount of annatto seeds commercialized in Brazil, $25 \%$ is used on the preparation of oily soluble and aqueous soluble extracts, and the remainder is used to manufacture the spice "colorífico", which is totally consumed by the domestic market mainly for home preparation. The aim of the present study was to determine bixin and norbixin amounts in annatto spices found in the market, by high performance liquid chromatography (HPLC). For this purpose, $\mathrm{C}_{18}$ column (Spherisorb ODS-2, $150 \times 4.6 \mathrm{~mm}, 3 \mu \mathrm{m}$ ) and acetonitrile/acetic acid $2 \%(65: 35)$ as mobile phase at $1 \mathrm{~mL} / \mathrm{min}$ were employed. The carotenoids were identified by their chromatographic behavior and UV-visible spectra obtained by the diode array detector and quantified by external standardization. Seven different brands of colorífico were analyzed (two to five lots from each brand), totaling 25 samples. The main coloring component found in the different brands was bixin, varying from 154 to $354 \mathrm{mg} / 100 \mathrm{~g}$. Norbixin was detected in trace amounts $(2-9 \mathrm{mg} / 100 \mathrm{~g})$. The variation of

\footnotetext{
${ }^{1}$ Recebido para publicação em 31/10/00. Aceito para publicação em 08/08/01.

${ }^{2}$ Aluna do curso de graduação de Engenharia de Alimentos, FEA/ UNICAMP

${ }^{3}$ Professora do Departamento de Ciência de Alimentos, Faculdade de Engenharia de Alimentos, UNICAMP, Caixa Postal 6121, Campinas, CEP 13083-970. E-mail:mercadan@obelix.unicamp.br ${ }^{*}$ A quem a correspondência deve ser enviada.
}

carotenoid levels among lots of the same brand was small, whereas, among different analyzed brands, the variation was wide.

Keywords: carotenoids; annatto; spice; colorífico; bixin; norbixin.

\section{1 - INTRODUÇÃO}

$\mathrm{Na}$ observação de um alimento o impacto visual causado pela cor sobrepõe-se a todos os outros, fazendo desse atributo um dos mais importantes na comercialização de alimentos e constituindo, assim, primeiro critério de aceitação ou rejeição de um produto.

Os corantes são empregados numa infinidade de alimentos e bebidas com o intuito de compensar a perda de cor durante o processamento industrial e estocagem, uniformizar a cor dos alimentos, e finalmente dar cor a alimentos originalmente incolores, tornandoos mais atrativos ao consumidor [1].

Dentre os corantes naturais, o urucum é o mais usado pela indústria brasileira, representando cerca de $90 \%$ dos corantes naturais usados no Brasil e $70 \%$ no mundo [7]. As preparações de urucum são usadas para colorir manteiga, queijos, produtos de panificação, óleos, sorvetes, cereais e embutidos.

Do total de sementes de urucum produzido no Brasil, cerca de $25 \%$ são utilizados na preparação de extratos lipo- e hidrossolúveis e o restante é usado na fabricação do colorífico, totalmente consumido no mercado interno [7]. Segundo a Resolução CNNPA 12/78 do Ministério da Saúde [2], o colorífico é definido como um produto constituído pela mistura de fubá ou farinha de mandioca, com urucum em pó ou extrato oleoso de urucum adicionado ou não de sal e de óleos comestíveis. Este produto, quase que exclusivamente de uso doméstico, proporciona cor avermelhada ao arroz, risotos, bifes, frangos, farofas, molhos e queijos. Seu principal mercado é a região Nordeste do país.

O urucueiro Bixa orellana L. é uma planta nativa da América Tropical [13]. Suas sementes são cobertas por uma resina vermelha que contém como pigmento principal o carotenóide bixina, cuja estrutura se encontra na Figura 1, sendo também o pigmento predominante nas preparações lipossolúveis [12, 13]. A norbixina (Figura 1), produto da saponificação da bixina, é o pigmento principal das preparações hidrossolúveis, sendo encontrada em pequena quantidade nas sementes e nas preparações lipossolúveis [12, 13].

Os carotenóides totais de urucum podem ser determinados através da leitura do extrato em espectrofotômetro [6,16]. A cromatografia líquida de alta eficiência (CLAE) tem sido empregada para separar bixina e norbixina [11, 14, 15]. Entretanto, a bixina e a norbixina 
de sementes de urucum não foram separadas no sistema CLAE empregado por WILBERG, RODRUIGUEZAMAYA [17], tendo ambos sido quantificados juntos.

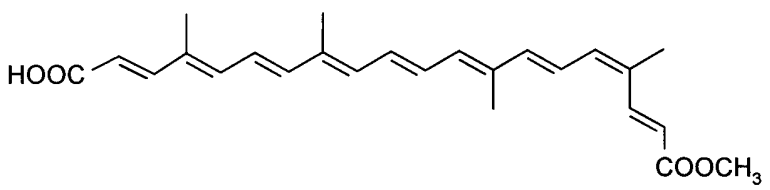

bixina

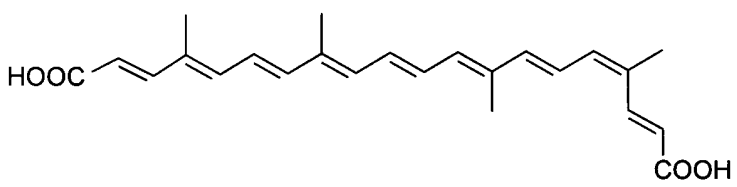

norbixina

FIGURA 1. Estrutura da bixina e da norbixina.

O objetivo do presente trabalho foi determinar, por CLAE, os teores de bixina e norbixina em várias marcas e lotes de colorífico.

\section{2 - MATERIAIS E MÉTODOS}

Devido ao longo sistema de duplas ligações conjugadas, os carotenóides são altamente susceptíveis à luz, oxigênio e altas temperaturas. Por esta razão, todas as operações foram conduzidas sob luz difusa e os extratos de carotenóides foram estocados sob $\mathrm{N}_{2}$ em congelador.

\section{1 - Amostras}

As amostras foram adquiridas durante os meses de novembro de 1998 a junho de 1999 no comércio de Campinas, São Paulo, Brasil. Foram analisadas amostras de diferentes lotes de sete marcas de colorífico, sendo 5 diferentes lotes das marcas A, B e C; 3 lotes das marcas $\mathbf{D}$ e $\mathbf{E}$; e 2 lotes das marcas $\mathbf{F}$ e $\mathbf{G}$, totalizando 25 amostras.

Todas as marcas apresentavam os ingredientes no rótulo da embalagem, entretanto a porcentagem de urucum adicionado ou o teor de bixina não constava do mesmo. Cabe esclarecer que esta situação está de acordo com a legislação brasileira vigente.

\section{2 - Extração}

Duas embalagens do mesmo lote foram homogeneizadas e desta mistura pesou-se aproximadamente $0,3 \mathrm{~g}$. Os pigmentos foram extraídos, em ultra-som, sucessivamente com 5, 4 e $3 \mathrm{~mL}$ de metanol. Em seguida, adicionaram-se $2 \mathrm{~mL}$ de acetona repetidamente, geralmente 2 vezes, até extração completa. Juntou-se todos os extratos em balão volumétrico de $50 \mathrm{~mL}$ e o volume foi completado com metanol. As análises foram conduzidas em triplicata. Antes da análise por CLAE, a amostra foi filtrada em membrana de $0,22 \mu \mathrm{m}$ de poro.
Algumas amostras, mesmo após a extração, permaneceram com uma leve coloração amarelada, possivelmente devido ao fubá utilizado como matéria-prima. Essa coloração não foi removida com diclorometano, eliminando a possibilidade de ser um dos carotenóides a ser quantificado, pois a bixina e a norbixina são muito solúveis em solventes clorados.

\section{3 - Cromatografia líquida de alta eficiência}

Para separar os carotenóides foi utilizado um cromatógrafo líquido de alta eficiência constituído de conjunto de bombeamento quaternário de solvente (Waters, modelo 600), detector de arranjo de diodos (Waters, modelo 996), injetor Rheodyne ("loop" de $20 \mu \mathrm{L}$ ), degaseificador "on-line" (Waters) e sistema de aquisição e processamento de dados Millenium (Waters). Os espectros foram adquiridos entre 300 e $600 \mathrm{~nm}$ e processados no comprimento de onda máximo de cada carotenóide.

Todas as separações foram conduzidas em coluna $\mathrm{C}_{18}$ (Spherisorb ODS-2, 150mmx4,6mm, tamanho de partícula $3 \mu \mathrm{m})$, com fluxo de $1 \mathrm{~mL} / \mathrm{min}$. Os solventes, grau cromatográfico, foram previamente filtrados em membrana de $0,45 \mu \mathrm{m}$ antes de serem utilizados no equipamento.

Várias combinações de solventes foram investigadas, mas a que apresentou melhor resultado foi acetonitrila: ácido acético 2\% (65:35) descrita por SCOTTER et al. [15], que separou os carotenóides incluindo isômeros em 22min, e cujos picos apresentaram-se simétricos, sem cauda e espectrofotometricamente puros.

Os picos correspondentes à bixina e norbixina foram identificados através do comportamento cromatográfico e comparação dos espectros no UV-visível fornecidos pelo detector de arranjos de diodos com os fornecidos na literatura [3, 5].

Para a quantificação da solução-padrão de bixina utilizou-se coeficiente de absorção de 2826 ( $\left.\lambda_{\max } 470 \mathrm{~nm}\right)$ em clorofórmio $[5,16]$ e para a da norbixina 3473 em

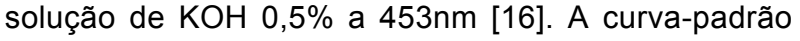
da bixina foi linear na faixa estudada (10 a $140 \mu \mathrm{g})$ e apresentou coeficiente de correlação $\left(R^{2}\right)$ de 0,996 , assim como a curva-padrão da norbixina na faixa de 6 a $34 \mu \mathrm{g}$ que mostrou $R^{2}$ de 0,968 . A quantificação dos carotenóides foi feita por comparação da área do pico da amostra com a área do padrão injetado diariamente.

\section{4 - Obtenção e purificação dos padrões}

Como os padrões de bixina e norbixina não estão disponíveis no mercado, deve-se sintetizar ou isolar estes carotenóides a partir de uma fonte natural dos mesmos.

\subsection{1 - Padrão bixina}

A bixina foi extraída com uma mistura de metanol: diclorometano (1:1), a partir das sementes de urucum, previamente lavadas com éter de petróleo. 
Após concentração, o extrato foi purificado por sucessiva cromatografia em camada delgada (CCD) de sílica-gel, ambas com acetato de etila/éter de petróleo (3:2) como fase móvel. Na primeira cromatografia, utilizando camadas preparadas no laboratório com sílica (Merck), duas bandas foram separadas, e a que permaneceu na origem foi raspada e eluída com metanol/ diclorometano (1:1). Após concentração, a banda foi novamente aplicada em placas prontas de sílica (Merck) onde ocorreu separação de duas bandas, e a principal $\left(R_{f}=0,61\right)$ foi raspada e eluída com metanol/diclorometano. O padrão obtido apresentou pureza de $97 \%$, verificada por CLAE.

\subsection{2 - Padrão norbixina}

Para a obtenção da norbixina, após evaporação do diclorometano, juntou-se ao extrato metanólico da semente de urucum uma solução metanólica de $\mathrm{KOH} 10 \%$ e deixou-se em temperatura ambiente, por uma noite, ao abrigo da luz. Desta maneira ocorreu saponificação da bixina originando a norbixina. A esta mistura foi, então, acrescentado ácido acético para neutralização e precipitação dos sais de norbixina que foram recolhidos por filtração.

O padrão dissolvido em acetato de etila foi purificado por coluna de sílica previamente condicionada com acetato de etila. Adicionou-se gradualmente metanol até o padrão ser recolhido com metanol 100\%.

Após análise por CLAE, o padrão de norbixina obtido mostrou conter $10 \%$ de isômeros. Tentativas de aumentar a pureza através de cromatografia em coluna aberta de $\mathrm{Ca}(\mathrm{OH})_{2}$, óxido de alumínio e sílica-gel não foram bem sucedidas.

\section{5 - Avaliação do método}

O limite de detecção da bixina e norbixina foi obtido realizando-se diversas injeções, com gradativas diluições.

Testes de recuperação foram realizados para avaliar a eficiência do método de extração, adicionando-se a uma amostra de colorífico, já quantificada, 529,0 $\mu \mathrm{g}$ de bixina e $6,29 \mu \mathrm{g}$ de norbixina. A solução padrão foi evaporada ficando aderida à amostra; e os carotenóides foram extraídos como descrito no item 2.2. Os testes foram realizados em triplicata.

As variações diárias e em dias diferentes das áreas dos picos dos padrões de bixina e de norbixina também foram avaliadas através do coeficiente de variação (C.V.).

\section{3 - RESULTADOS E DISCUSSÃO}

\section{1 - Recuperação, precisão e limite de detecção}

Nas condições deste estudo, o limite de detecção foi de $0,018 \mu \mathrm{g} / \mathrm{mL}$ para bixina e de $0,017 \mu \mathrm{g} / \mathrm{mL}$ para norbixina.

A recuperação média do método, incluindo a etapa de extração do colorífico, para a bixina foi de $100 \%$ (variando de 95 a 105\%) e de $102 \%$ para a norbixina (variando de 100 a 106\%). Estes resultados mostraram que o método utilizado apresenta uma ótima exatidão.

Os testes realizados com padrões comprovaram que, apesar da variação diária da área do pico ser baixa, com C.V. médio de $1 \%$ tanto para bixina como para norbixina, o mesmo não ocorreu com a variação em dias diferentes (6\% para a bixina e $8 \%$ para norbixina). A alta variação entre dias das áreas dos picos comprovou a necessidade de se verificar diariamente a concentração de cada carotenóide. Entretanto, KIMURA [10] reportou valores de C.V. menores que $4 \%$ quando a concentração de vários carotenóides de folhas foi quantificada através de suas curvas-padrão e de um ponto após 30 dias. HSIEH, KAREL [9] reportaram, para cenoura, C.V. de $4 \%$ para 5 injeções de $\beta$-caroteno e HAMANO, MERCADANTE [8] encontraram os seguintes C.V., para injeções em triplicata de amostras de polpa e suco de cajá, 0 a $7 \%$ para $\beta$-caroteno, 0 a $3 \%$ para $\alpha-$ caroteno, 0 a $3 \%$ para $\beta$-criptoxantina, 0 a $2 \%$ para zeinoxantina e de 0 a $4 \%$ para luteína.

Do total de 25 amostras analisadas, apenas em 6 amostras os teores de bixina apresentaram C.V. maior que $3 \%$ entre as triplicatas, comprovando, assim, a boa precisão do método. Já para a norbixina os valores de C.V. foram maiores, variando de 2 a $21 \%$. Esse resultado era esperado, visto que a sua concentração nas amostras foi cerca de 100 vezes menor que a da bixina e apenas 10 vezes maior que o limite de detecção. BUSHWAY, WILSON [4], analisando produtos de cenoura, encontraram C.V. de 1 a $14 \%$ para $\alpha$-caroteno e de 1 a $9 \%$ para $\beta$-caroteno; e em produtos de cajá HAMANO, MERCADANTE [8] também relataram valores de C.V. na faixa de 1 a $12 \%$ para $\beta$-caroteno, 1 a $14 \%$ para $\alpha$-caroteno, 1 a $15 \%$ para $\beta$-criptoxantina, 1 a $13 \%$ para zeinoxantina e de 0 a $10 \%$ para luteína. Não foram encontrados na literatura valores de C.V. relativos à bixina e norbixina.

\section{2 - Composição de carotenóides de colorífico}

Todas as amostras de colorífico analisadas neste estudo continham bixina como o carotenóide majoritário e norbixina em menor quantidade, como mostra o cromatograma da Figura 2. Este resultado era esperado, uma vez que a bixina perfaz cerca de $80 \%$ dos carotenóides totais da semente de urucum [13] e um dos ingredientes do colorífico é o urucum ou sua suspensão oleosa.

Os teores de bixina e norbixina encontrados nas marcas de colorífico analisadas estão apresentados na Tabela 1. Os teores de bixina variaram de 154 a 354 $\mathrm{mg} / 100 \mathrm{~g}$ e os de norbixina de 2,1 a 6,6 mg/100g.

Os teores de bixina entre os lotes da mesma marca tiveram uma variação de 3 a $14 \%$, indicando que as indústrias possuem um bom controle da matéria-prima e do processo. Entretanto algumas marcas, como $\mathbf{D}$ e E, apresentaram cerca do dobro de bixina que as de- 
mais. Estes resultados indicam que é necessário que este tipo de produto possua um padrão de identidade e qualidade a ser seguido por todas as indústrias fabricantes.

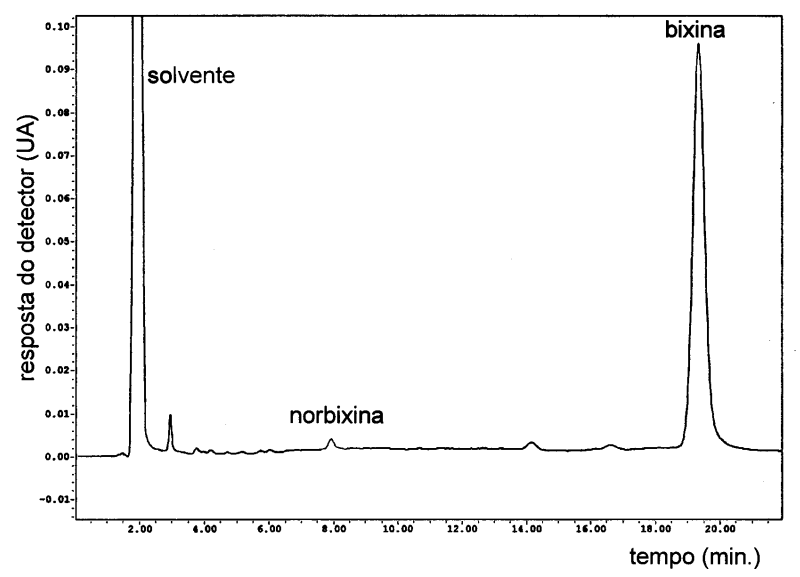

FIGURA 2. Cromatograma, obtido por CLAE, de carotenóides de colorífico. Condições cromatográficas: coluna Spherisorb ODS-2 e acetonitrila:ácido acético $2 \%$ (65:35) como fase móvel com fluxo de $1 \mathrm{~mL} / \mathrm{min}$.

TABELA 1. Teores de carotenóides em amostras de colorífico.

\begin{tabular}{ccc}
\hline Marcas & bixina $(\mathrm{mg} / 100 \mathrm{~g})$ & norbixina $(\mathrm{mg} / 100 \mathrm{~g})$ \\
\cline { 2 - 3 } & média \pm D.P. & média \pm D.P. \\
\hline $\mathbf{A}^{\mathrm{a}}$ & $185 \pm 11$ & $5,9 \pm 3,0$ \\
$\mathbf{B}^{\mathrm{a}}$ & $229 \pm 26$ & $3,2 \pm 1,0$ \\
$\mathbf{C}^{\mathrm{a}}$ & $154 \pm 18$ & $2,1 \pm 0,3$ \\
$\mathbf{D}^{\mathrm{b}}$ & $320 \pm 19$ & $4,5 \pm 0,4$ \\
$\mathbf{E}^{\mathrm{b}}$ & $354 \pm 10$ & $6,6 \pm 1,1$ \\
$\mathbf{F}^{\mathrm{c}}$ & $202 \pm 28$ & $3,3 \pm 0,6$ \\
$\mathbf{G}^{\mathrm{c}}$ & $154 \pm 1$ & $3,6 \pm 0,1$ \\
\hline
\end{tabular}

Média e desvio padrão de ${ }^{\mathrm{a}} 5$ lotes, ${ }^{\mathrm{b}} 3$ lotes e ${ }^{\mathrm{c}} 2$ lotes.

\section{4 - CONCLUSÕES}

O método avaliado mostrou ser preciso, exato e prático, levando em torno de 30 minutos cada análise.

Os resultados indicaram que as indústrias produtoras de colorífico possuem um bom controle da matéria-prima e do processo, entretanto houve uma variação de até $100 \%$ entre os teores de carotenóides das diferentes marcas.

Recomenda-se que seja estabelecida uma quantidade de urucum a ser adicionada ao colorífico, que pode ser controlada através da quantidade de bixina, com a finalidade de uniformizar a coloração deste tipo de produto.

\section{5 - REFERÊNCIAS BIBLIOGRÁFICAS}

[1] ANGELUCCI, E. Corantes naturais versus corantes artificiais: vantagens e desvantagens. In: Seminário de Corantes Naturais para Alimentos, p. 8-10, 1989. Campinas.

[2] BRASIL. Leis, decretos, etc. - Resolução n 12/78 da Comissão Nacional de Normas e Padrões para Alimentos. Diário Oficial da União, Brasília, 24 jul. 1978.

[3] BRITTON, G. UV/Visible Spectroscopy. In: BRITTON, G.; LIAAEN-JENSEN, S.; PFANDER, H. (Eds.) Carotenoids: Spectroscopy. Birkhäuser: Basel. 1995. v. 1B, p. 13-62.

[4] BUSHWAY, R.J.; WILSON, A.M. Determination of $\alpha-$ and $\beta$ carotenes in fruit and vegetables by high performance liquid chromatography. Can. Inst. Food Sci. Technol. J., v. 15, p. 165-169, 1982.

[5] DAVIES, B.H. Carotenoids. In: GOODWIN, T.W. (Ed.) Chemistry and Biochemistry of Plant Pigments. Academic Press: London. 1976. v. 2, p. 38-165.

[6] FOOD AGRICULTURE ORGANIZATION. FAO and Food Nutrition Paper 52, Add. 4. Compendium of Food Additive Specification, p. 11-17, Roma, 1996.

[7] GHIRALDINI, J.E. Produção e comercialização interna de corantes naturais para alimentos. In: Seminário de Corantes Naturais para Alimentos, p. 20-25, 1989. Campinas.

[8] HAMANO, P.S.; MERCADANTE, A.Z. Composition of carotenoids from commercial products of caja (Spondias lutea). J. Food Composition Anal., v. 14, 2001 (no prelo).

[9] HSIEH, Y.P.; KAREL, M. Rapid extraction and determination of $\alpha$ - and $\beta$-carotenes in foods. J. Chromatogr., v. 259, p. 515-518, 1983.

[10] KIMURA, M. Aprimoramento da metodologia para determinação de carotenóides em alimentos. Campinas, 2000. 96 p. Tese de Doutorado, Faculdade de Engenharia de Alimentos, Universidade Estadual de Campinas (UNICAMP).

[11] LANCASTER, F.E.; LAWRENCE, J.F. Determination of annatto in high-fat dairy products, margarine and hard candy by solvent extraction followed by high-performance liquid chromatography. Food Add. Contamin., v. 12, p. 9-19, 1995.

[12] MERCADANTE, A.Z.; PFANDER, H. Carotenoids from annatto: a review. Recent Res. Devel. Agric. Food Chem., v. 2, p. 79-91, 1998

[13] PRESTON, H.D.; RICKARD, M.D. Extraction and chemistry of annatto. Food Chem., v. 5, p. 47-56, 1980.

[14] ROUSEFF, R.L. High performance liquid chromatographic separation and spectrral characterization of pigments in turmeric and annatto. J. Food Sci., v. 53, p. 1823-1826, 1988.

[15] SCOTTER, M.J.; THORPE, S.A.; REYNOLDS, S.L.; WILSON, L.A. \& STRUTT, P.R. Characterisation of the principal colouring components of annatto using high performance liquid chromatography with photodiode-array detection. Food Add. Contam., v. 11, p. 301-315, 1994.

[16] TAKAHASHI, M. Monografia de Corantes Naturais para Fins Alimentícios. Padrões de Identidade e qualidade. p. 2229, São Paulo, 1987.

[17] WILBERG, V.C.; RODRIGUEZ-AMAYA, D. Quantificação dos carotenóides de sementes de urucum (Bixa orellana L.) por cromatografia líquida de alta eficiência. Rev. Bras. Cor. Nat., v. 1, p. 145-152, 1992.

\section{6 - AGRADECIMENTOS}

Os autores agradecem ao CNP/PIBIC/UNICAMP pela bolsa de Iniciação Científica ao primeiro autor; à FAPESP (projeto 97/06423-6) e ao MCT/FINEP/CNPq (PRONEX projeto 4196091500 ) pelo auxílio financeiro. 